\title{
Symposium review: Genomic selection for reducing environmental impact and adapting to climate change*
}

\author{
Jennie E. Pryce ${ }^{1,2} \dagger$ ๑ and Mekonnen Haile-Mariam ${ }^{1}$ (ㄷ) \\ ${ }^{1}$ Agriculture Victoria Research, AgriBio, Centre for AgriBioscience, Bundoora, Victoria 3083, Australia \\ ${ }^{2}$ School of Applied Systems Biology, La Trobe University, Bundoora, Victoria 3083, Australia
}

\section{ABSTRACT}

The world has been warming as greenhouse gases accumulate. Worldwide from 1880 to 2012, the average surface temperature has increased by about $0.85^{\circ} \mathrm{C}$ and by $0.12^{\circ} \mathrm{C}$ per decade since 1951 . The world's cattle population is a contributor to atmospheric methane, a potent greenhouse gas, in addition to suffering from high temperatures combined with humidity. This makes research into reducing the global footprint of dairy cows of importance on a long-term horizon, while improving tolerance to heat could alleviate the effects of rising temperatures. In December 2017, genomic estimated breeding values for heat tolerance in dairy cattle were released for the first time in Australia. Currently, heat tolerance is not included in the Balanced Performance Index (Australia's national selection index), and the correlation between heat tolerance breeding values and Balanced Performance Index is -0.20 , so over time, heat tolerance has worsened due to lack of selection pressure. However, in contrast, sizable reductions in greenhouse gas emissions have been achieved as a favorable response to selecting for increased productivity, longevity, and efficiency, with opportunities for even greater gains through selecting for cow emissions directly. Internationally considerable research effort has been made to develop breeding values focused on reducing methane emissions using individual cow phenotypes. This requires (1) definition of breeding objectives and selection criteria and (2) assembling a sufficiently large data set for genomic prediction. Selecting for heat tolerance and reduced emissions directly may improve resilience to changing environments while reducing environmental impact.

Key words: methane, heat tolerance, genomic selection, global warming

Received October 11, 2019.

Accepted December 3, 2019.

*Presented as part of the Joint ADSA/Interbull Symposium: Breeding and Genetics Data Pipelines for Implementation of Genomic Evaluation of Novel Traits at the ADSA Annual Meeting, Cincinnati, Ohio, June 2019.

†Corresponding author: jennie.pryce@agriculture.vic.gov.au

\section{INTRODUCTION}

The world has been warming as greenhouse gases accumulate. From 1880 to 2012, the average surface temperature has increased by about $0.85^{\circ} \mathrm{C}$ (IPCC, 2013). By 2030, Australian annual average temperatures are projected to increase by 0.6 to $1.3^{\circ} \mathrm{C}$ above the climate of 1986-2005 (CSIRO and Bureau of Meteorology, 2015). This is anticipated to lead to longer periods of drought and lower production levels and may be especially damaging in countries that are vulnerable to the effects of climate change, such as Australia (CSIRO and Bureau of Meteorology, 2015).

Methane has approximately 28 times the global warming potential of $\mathrm{CO}_{2}$, and dairy cattle account for $20 \%$ of the global livestock sector's greenhouse gas emissions and about one-half of this is from enteric methane emissions (Gerber et al., 2013). As markets around the world increasingly demand information on the carbon footprint of consumer products, such as dairy, reducing methane emissions is an important goal. By increasing overall efficiency of production over the last few decades, the dairy industry has contributed to the global reduction of greenhouse emission by producing the same or more milk from fewer cows (e.g., Bell et al., 2013; Pryce and Bell, 2017).

Heat stress reduces DMI and milk production (West, 2003), fertility (De Rensis and Scaramuzzi, 2003; Hansen, 2007), and the welfare of cattle. Compounding the issue, intense selection on production traits has led to a reduction in heat tolerance, as genetic correlations between milk production and heat tolerance are unfavorable (Nguyen et al., 2017a). So, although selecting for increased yield may dilute the effects of global emissions per liter (e.g., Pryce and Bell, 2017), there is still a need to consider heat tolerance, in addition to other traits of importance, that are unfavorably correlated with milk production traits.

The global cattle population contributes to and suffers from the effects of global warming. This makes research into reducing the global footprint of dairy cows of high importance as a medium to long-term strategy, whereas in the short term, improving tolerance to heat 
could alleviate the effects of rising temperatures. In this paper we discuss the role of genetic selection to counter the effects of climate change; while acknowledging the challenge of global warming requiring global solutions, we will cover genetic selection in dairy approaches being applied in Australia, including a proactive solution (reducing emissions) and a reactive solution (breeding for heat tolerance).

\section{SELECTING FOR REDUCED METHANE EMISSIONS}

Ruminants are unique in that microorganisms break down feeds rich in cellulose in the rumen to produce VFA such as acetate, propionate, and butyrate. The products of this fermentation process include $\mathrm{H}_{2}$ and $\mathrm{CO}_{2}$, which methanogenic archaea in the rumen reduce to methane (Danielsson et al., 2017). Methane production represents a loss of energy efficiency of around 2 to $12 \%$ (Johnson and Johnson, 1995), so it is important from a feed efficiency perspective in addition to its impact on the environment.

Two groups of strategies can be used to mitigate methane emissions, and these include those that can be implemented immediately, such as dietary interventions, and longer-term solutions, such as selection. Evidence is growing that manipulating the diet fed to dairy cows can reduce methane emissions; for example, including using feedstuff high in lipids, such as brewer's grains, cold-pressed canola, grape marc, and wheat (Moate et al., 2016); plant compounds, such as tannins (Liu et al., 2011), and methane inhibitors, such as monensin (Waghorn et al., 2008). Other options that require additional research could include vaccines to reduce the population of ruminal methanogens (Williams et al., 2009).

Genetic selection could offer a permanent solution to methane emissions through either selecting for traits that have beneficial effects on emissions, or by identifying cows that are low emitters. Several studies have reported a sizable genetic variation in methane emissions of cattle (de Haas et al., 2011; Lassen and Løvendahl, 2016; Manzanilla-Pech et al., 2016; Negussie et al., 2017). The heritability of methane emission varies over the lactation and possibly over the lifetime of the animal because it is closely associated with feed intake (Breider et al., 2019).

\section{Indirect Selection}

From an emissions perspective, an increase in per cow yield has diluted the production of methane per liter of milk produced, although this is not true universally, especially in countries where little improvement in milk production has been achieved (Capper and
Bauman, 2013). From 1945 to 2015, the United States has witnessed about a 4 -fold increase in yield to around 10,000 kg (Britt et al., 2018). Over the same time period, Capper et al. (2009) calculated that the carbon footprint per billion liters of milk in 2007 was $37 \%$ of the equivalent milk production in 1944. Furthermore, the lower BW and milk volume of Jersey cows results in lower emissions per ton of cheese produced compared with Holsteins (Capper and Cady, 2012). So, reductions in greenhouse gas emissions have largely been achieved by selecting for increased productivity and efficiency.

There may be an opportunity to make even more progress in reducing emissions through selecting for feed efficiency directly. de Haas et al. (2011) suggested that by selecting for more efficient cows, methane production could be reduced by up to $26 \%$ over a $10-y r$ time frame. Richardson et al. (2020) recently set out a framework to determine the reduction in greenhouse gas emissions from improved feed conversion efficiency; they found that having $1 \mathrm{~kg}$ of more efficiently converted feed was estimated to be worth $3.23 \mathrm{~kg}$ of DMI and $0.055 \mathrm{~kg}$ of methane, worth Can $\$ 0.82$ (US\$0.63) and Can\$0.07 (US\$0.05), respectively. However, currently few countries have financial incentives to reduce emissions, although financial incentives that are social or environmental could change this (Negussie et al., 2017). Provision of direct or indirect financial incentives are being considered seriously by major dairy producers around the world. For example, the New Zealand government estimated that methane emissions from livestock needed to be reduced by 10 to $22 \%$ by 2050 to restrict increases in global temperature (Zhang et al., 2019). These authors argue that genetic selection for reduced emissions is the most promising strategy that will enable New Zealand to achieve this target economically.

The global population (in 2016) was about 270 million dairy cows producing 6.5 billion tonnes of milk (Van Eenennaam, 2019), which is on average 2,400 kg/ cow. Consequently, there is obviously a large amount of variation between countries in methane emissions per liter of milk produced, being much higher in countries with low production. So, first there is scope to reduce global emissions from the dairy sector through selecting for increased milk yields in low-producing countries, although the challenges in achieving this are significant and not without consequence.

In countries where milk yield per cow is comparatively high, there is also considerable value in selecting for longevity, fertility, and improved efficiency over the lifetime of cows. Garnsworthy (2004) and Bell et al. (2013) found that improving fertility could reduce emissions by requiring fewer replacements; the same is also true through breeding for longevity. Bell et al. 
(2013) found that a desirable increase in both net income and reduced emissions intensity per cow and per kilogram of milk solids in Australian dairy herds could be achieved by an increase in survival and reductions in milk volume, live weight, DMI, SCC, and calving interval. In a corresponding study considering the UK national breeding objective (Bell et al., 2015), a reduction in milk volume (and increase in milk solids), live weight and DMI (gross and metabolic efficiency, respectively), and increase in health, fertility, and overall survival were predicted to increase farm profit of UK dairy systems and reduce the environmental impact through greenhouse gas emissions.

\section{Breeding Objective Traits}

One of the challenges associated with developing breeding values to reduce methane emissions is to define a suitable breeding objective. Even though metrics to assess the effect of mitigation strategies include methane intensity (defined as methane per unit of product), or methane yield (methane per unit of feed intake), the trait that should be the focus of genetic selection practices is a trait associated with gross methane emissions. One approach is to take a trait analogous to residual feed intake, except in the case of methane, it is the difference between actual methane and predicted methane (de Haas et al., 2017). For example, predicted methane could be calculated using DMI and milk production; when subtracted from measured methane, the result is a residual methane trait.

Residual methane traits were explored by Manzanilla-Pech et al. (2016) in beef cattle, where residual methane was calculated by applying a genetic or phenotypic regression model that included methane corrected for $\mathrm{DMI}$ and $\mathrm{BW}$, with the idea being that either genetic or phenotypic correlations with these traits are zero. They found residual methane traits to be heritable (0.15-0.19), which illustrates that there is genetic variation in methane that is independent of DMI and BW. In dairy cattle the same approach can be applied, except that for lactating cows, methane could be corrected for DMI and milk yield. If growing animals are used, then BW could also be included. The regression approach avoids the pitfalls of ratio traits in animal breeding (Berry and Crowley, 2013). The desired EBV would be from animals that emit less methane than expected for their level of milk production, BW, and DMI. Breider et al. (2019) estimated that genetic correlations between methane production and milk yield were positive (0.49 to 0.54 ), so care needs to be taken when selecting for reduced methane production to avoid decreasing milk yield.
Another option is measuring methane emissions at different life stages. Methane emissions closely mirror the lactation curve (Negussie et al., 2017; Breider et al., 2019), so accounting for lactation stage is important. It is possible that methane emissions in calves is correlated with methane emissions in lactating cows, but research is required to verify this. It may also be more powerful to identify bulls that are lower emitters on the assumption that as a heritable trait, this characteristic will be transmitted to their daughters.

\section{Genomic Selection}

Genomic selection has been an enabling technology in this space, maximizing the investment made in collecting high-value phenotypes, such as individual cow records on emissions.

For most traditionally evaluated traits where large amounts of phenotypic data are collected at the national level, for example, milk production records, fertility, and so on, the genomic reference population is usually composed of bulls with large daughter groups (Chesnais et al., 2016). This means that genomically and traditionally (pedigree) derived breeding values are available simultaneously. Often the breeding value that is published comprises information from the animal's pedigree, including progeny and ancestors in addition to the genomic component. However, for expensive or difficult to measure traits, such as methane emissions and heat tolerance, it is often not cost effective to phenotype large daughter groups. Simulation studies, for example, McHugh et al. (2011), Gonzalez-Recio et al. (2014), and Dehnavi et al. (2018), have shown that for novel or expensive-to-measure traits it is generally more effective to genotype females instead of males, where genotyped females have the phenotype measured directly. The limitation with female reference populations is that cow data are often biased due to preferential treatment, leading to reduced accuracy of genomic prediction (Dehnavi et al., 2018).

One approach is to select entire herds on the basis of the quality of their records, which is the strategy being applied in the Australian Genomic Information Nucleus (Ginfo). Ginfo started in 2013 with around 100 herds and 30,000 cows and has contributed to the increase of reliabilities of genomic EBV and played a key role in development of genomic breeding values of novel traits (Pryce et al., 2018).

In some circumstances, phenotypes are too expensive or too difficult to be measured in dedicated female reference populations, and methane emissions and DMI fall into that category. For traits such as methane emissions, specialist equipment is often required with highly 
trained individuals to operate and use the equipment/ method appropriately, which is why for gathering data on these traits, research herds are often preferred. It should be noted, however, that considerable advances in new techniques have been made that could make easy and cheap measurements possible and in turn high-throughput options for measuring methane in commercial populations. However, these methods still require appropriate calibration for establishment and routine measurements.

\section{Measuring Methane}

Several methods to measure per cow methane emissions are available. These include enclosed respiration chambers, sulfur hexafluoride tracer technique $\left(\mathrm{SF}_{6}\right)$, handheld laser methane detection, automated head chambers (e.g., GreenFeed system), and sensors in automated milking systems. While all approaches have measurement error, the desire to screen large numbers of animals in genomic selection does not justify the use of inaccurate measurements (Hammond et al., 2016). For a comprehensive review comparing different measurement techniques, refer to Hill et al. (2016).

\section{Mid-Infrared Spectroscopy}

Mid-infrared (MIR) spectroscopy involves passing a beam of light through a milk sample to provide data in the form of spectra (absorbance or reflectance at specific wavelengths). Farmers currently receive regular reports from their herd test centers with information on milk volume and fat and protein concentration. Analysis of milk MIR has been used to predict other milk characteristics such as fatty acids, protein composition, coagulation properties, acidity, mineral composition, and ketone bodies with reasonable accuracy (De Marchi et al., 2014). The appeal with MIR is that potentially it is a cheap way of getting individual cow records for expensive and hard to measure phenotypes, such as methane production. Ideally MIR predictions of methane should be used as correlated traits to a measured selection objective.

Considerable effort has been put into using MIR to predict methane production. For example, Vanlierde et al. (2015) used 446 methane records from 142 cows from Belgium and Ireland to obtain coefficients of determination of $>0.75$ of predicted versus measured methane. Wang and Bovenhuis (2019) used MIR to predict breath sensor methane of 801 cows from 10 dairy farms. Using random cross-validation, the coefficient of determination was 0.49. However, as soon as the prediction was validated externally (i.e., using each farm as a validation block), the coefficient of determi- nation decreased to 0.01 , indicating that in their study random cross-validation is over optimistic and emphasizing the importance of cross-validation in developing MIR prediction equations. It is also worth checking the accuracy of prediction in herds with similar production environments, rather than across environments. Some results show that consistent ranking of animals using MIR-predicted methane emission is possible (Denninger et al., 2019) and may be accurate enough for genomic selection. In 2017 in a study that included data from 5 countries, calibration and cross-validation coefficients of determination of MIR predictions of $>0.65$ and 0.57 were obtained (Vanlierde et al., 2018). Global collaboration in this area should remain a research priority.

\section{Sharing Phenotypes Internationally}

Other than obtaining high-throughput phenotypes from screening large numbers of genotyped animals in genomic reference populations, sharing data sets is another option. This has been a popular approach for feed efficiency traits. A successful example of this is the global dry matter initiative (gDMI) that culminated in the genomic prediction of dry matter intake using a reference population of around 10,000 cows (Berry et al., 2014). More recently, the Efficient Dairy Genome Project, which is a multi-national research initiative led by Canada, shares data for genomic prediction of methane production, feed intake, or residual feed intake, and as of December 2018 has collated 882,573 records from 4,704 cows (F. Schenkel, University of Guelph, ON, Canada; personal communication). Each partner has free access to the database that includes methane, DMI, milk production, and live weight phenotypes in addition to pedigree and genomic information. The International Committee on Animal Recording also has a mandate to facilitate sharing and standardizing methane phenotypes.

Because many methods that exist to measure phenotypes and standards for recording are not currently in place, there has been a requirement to develop statistical methods to combine heterogeneous data (Haas et al., 2018). In addition to multi-country reference populations, there may also be an advantage to bringing together data on different breeds, such as beef breeds, which has been successful for residual feed intake (Khansefid et al., 2014).

Eventually and probably through concerted international efforts (de Haas et al., 2017), EBV to reduce methane emissions directly are likely to become available. As with other traits, the most effective way to select for methane reduction will be through multi-trait selection indices, which will account for (co)variances between methane traits and other traits under selec- 
tion correctly. In the short term, there is potential to reduce emissions through selection for other traits in the breeding objective, such as longevity and fertility. This can be achieved by revising the economic values in selection indices to include carbon credits (Bell et al., 2013).

\section{Rumen Metagenome}

The rumen microbiome is diverse and complex; however, Wallace et al. (2019) argued that the rumen productivity and function is largely dictated by a core group of microorganisms that are heritable (consistent across feeding systems and geographical regions) with estimates ranging between 0.2 and 0.6. The authors of this paper go on to propose a microbiome-led genetic solution to lowering ruminant emissions.

It is necessary to develop methods to combine information from multiple sources to improve prediction and gain knowledge into the basic biology underlying methane traits. For example, by combining measured phenotypes, whole-genome sequence data, the rumen metagenome, the proteome/metabolome (protein and metabolite structure and function), and functional genomic assays (e.g., methylation, transcriptomics, and so on), it is possible to identify causal variants, which should lead to better responses to selection (Rexroad et al., 2019). Ultimately, multi-omics approaches could enhance selection to reduce methane emissions, in addition to other evaluated traits.

\section{SELECTING FOR HEAT TOLERANCE}

Heat tolerance has been defined as the ability to maintain thermal stability at high temperatures and humidity (Carabaño et al., 2019); this process is largely controlled by the capacity to dissipate heat generated by metabolic heat production. Factors that affect heat dissipation include body surface area, sweating rate, panting, coat characteristics (length, thickness, color, and so on), in addition to the rate of metabolic heat production, which is higher for demanding metabolic processes, such as lactation.

Rectal or vaginal temperature is a direct measure of body temperature regulation that has been shown to be heritable (Dikmen et al., 2012). From a practical perspective that is applicable to dairy cattle, changes in production and reproductive performance of cattle are outcomes associated with heat stress (West, 2003; Das et al., 2016) that are convenient breeding targets (Carabaño et al., 2019). Because heat tolerance is unfavorably correlated with milk production traits (Nguyen et al., 2017a), it is likely that selection objectives focused on high yielding dairy cows will be detrimental to heat tolerance. Nguyen et al. (2017a) noted a declining genetic trend for heat tolerance in Australian Holstein and Jersey dairy cattle at a rate of $0.3 \% / y$. This decline coupled with more frequent high heat events makes heat tolerance an important consideration, especially for countries/regions where heat/humidity is already an issue for production.

To study heat stress in cattle, a temperature-humidity index (THI) is commonly used as a bioclimatic index (LeRoy Hahn et al., 2009). The THI combines temperature and humidity into a single value that combines air temperature with humidity. Bohmanova et al. (2007) compared 7 ways of calculating THI and concluded that humidity and temperature were the limiting factors in humid and dry climates, respectively.

While the use of sprinklers and shade are effective management solutions for reducing the risk of heat stress, genetic selection may provide an effective longterm solution. Genetic solutions could be beneficial as the use of sprinklers and other cooling devices requires the use of electricity and the provision of shade may not be possible in pasture-based environments where the production system is inherently efficient.

\section{Genetic Solutions}

Several strategies should be considered for genetically altering heat tolerance, including (1) choice of breed or cross (some breeds are more heat tolerant than others), (2) introgression of genes associated with thermotolerance, and (3) genomic selection using selection criteria associated with heat tolerance.

\section{Choice of Breed or Use of Crosses}

In tropical climates, Bos indicus are often crossed with temperate dairy breeds to combine heat and parasite resistance of Bos indicus with production qualities of temperate breeds (Davis et al., 2017; Burrow et al., 2019). Temperate breeds do show some variation in heat tolerance; for example, New Zealand Holsteins appear to exhibit greater reductions in milk yield in hotter climates than Jerseys or crossbreds (Bryant et al., 2007). In fact, in New Zealand reductions in yield were observed when temperatures exceed 21 and $25^{\circ} \mathrm{C}$, respectively, at $75 \%$ humidity for Holsteins and Jerseys, respectively (Bryant et al., 2007).

\section{Slick Hair Locus}

Introgression involves incorporating favorable known alleles, often from a completely different breed (e.g., the slick hair gene from Senepol). Traditionally introgression includes crossing back to the original breed to 
restore the favorable dairy characteristics from the base breed; this process takes several generations of crossing and is therefore time consuming and inefficient. The mutation that confers the slick coat phenotype is a deletion in an exon of the prolactin receptor in Senepol cattle (Littlejohn et al., 2014) (http://omia.angis.org .au/OMIA001372/9913/). The so-called slick coat mutation appears to be mainly associated with the coat type, with some alteration to sweating ability being a possibility (Davis et al., 2017). Breeding programs have already started incorporating the slick mutation in Holstein cattle (Carabaño et al., 2019).

Dikmen et al. (2014) compared thermoregulation of Holstein cows with the slick hair phenotype compared with the wildtype (non-slick) alternative. They conducted 2 experiments, one where cows were housed in freestall barns during the summer and the other with acute heat stress (a dry lot with minimal shade). In both experiments the internal body temperatures (vaginal/rectal) were lower in slick-haired cows. The authors concluded that slick hair cattle have superior thermoregulatory ability compared with non-slick animals.

Gene editing could revolutionize genetic change in traits such as heat tolerance by precisely introducing the favored allele in a single edit (Van Eenennaam, 2019). Although gene editing is particularly suited to qualitative traits affected by a single gene, such as slick, recent advances in gene editing techniques mean that it is now possible to edit many alleles simultaneously (Campa et al., 2019), facilitating more complex gene networks. As our knowledge of genes controlling heat tolerance grows, the role of gene editing could increase.

\section{Selection Criteria}

Selection criteria for heat tolerance could include body temperature, respiration rate, heart rate, sweating rate, reduction in intake, or milk yield. However, for practical purposes the effect of THI on production traits is often favored (Carabaño et al., 2019). Although EBV for milk production traits can already include the effect of heat, this is only true when cows are evaluated under heat stress conditions. Quite often this is not the case and could become more of an issue in the genomic era where this information is unlikely to be captured in conventional production EBV. The EBV for heat tolerance are especially important in grazing environments typical of the dominant production systems in Australia and New Zealand, for instance, because other mitigation strategies, such as installation of cooling equipment, are simply not practical at grazing.

Most dairy studies to date have used the so-called broken stick model to model the level of milk production traits under thermo-neutral conditions and the slope of decay after passing a threshold associated with a transition to heat stress (Bernabucci et al., 2014). An alternative is to model using a reaction norm; this approach uses polynomials and therefore is more flexible than the broken stick approach (Carabaño et al., 2019), for example, if the slope gets steeper at higher THI levels.

Other measures of heat tolerance include body temperature and respiration rate (Dikmen et al., 2012). Many modern internal (intra-vaginal or rectal) devices are now capable of continuously logging data; however, the limitation is that these can only be used for short periods of time and are comparatively expensive, making them unsuitable for large-scale measurement. Nevertheless, Dikmen et al. (2012) determined that the heritability of rectal temperatures under heat stress conditions was 0.17 . Panting scores could be a viable alternative for assessing heat load (Gaughan et al., 2008), although there are still limitations to how many cattle can be assessed. Recent advances in sensor device technology might make measuring panting feasible, as many wearable sensor devices are now capable of measuring heavy breathing on an almost continuous basis. Bar et al. (2019) found good concordance between accelerometer measures of lactating cows breathing heavily and vaginal temperatures. As wearable devices are becoming more popular, this could be an excellent opportunity for developing large data sets for estimation of breeding value on the ability of animals to tolerate heat.

Other selection criteria that could be worth considering include metabolites that change under heat stress. The review by Ríus (2019) describes how breakdown of whole-body protein and synthesis of urea increases under heat stress, suggesting that AA are mobilized to meet the animal's requirements. The limitation with this type of approach has been to obtain phenotypes on a sufficiently large population for genetic evaluation purposes. One option is to use MIR because this should detect the biomarkers associated with variation in heat tolerance that are present in milk (König and May, 2019). Hammami et al. (2015) found that several milk fatty acids predicted using MIR were sensitive to heat stress, most notably C18:1 cis-9, which is known to reflect body tissue mobilization and could indicate that cows with depressed appetites and yields mobilize proportionately more body reserves.

Heat affects dairy cows in other ways. For example, Dahl et al. (2016) stated that heat stress reduces DMI, which in turn reduces yield and compromises immune function; furthermore, if heat events are experienced in late gestation, calf survival and adult performance are affected. Alternatively, indicators of recovery after a heat event could also be useful selection criteria. Many 
of these traits are correlated. For example, evidence indicates that traits associated with disease or parasite resistance are favorably correlated with heat tolerance (Mackinnon et al., 1991; Burrow et al., 2019). This is an important concept in defining new breeding objectives and corresponding selection criteria for traits associated with adaptation and robustness across a broad range of environments.

\section{Implementation of Genetic Evaluations for Heat Tolerance Australian Example}

Nguyen et al. (2016) found that using high-density SNP genotypes, heat tolerance modeled using a random regression model assuming the THI threshold is 60, equivalent to a daily temperature of $20^{\circ} \mathrm{C}$ and $45 \%$ relative humidity, gives a genomic prediction accuracy of 0.42 to 0.61 . Heat tolerance breeding values were unfavorably correlated with milk production traits, but were favorably associated with fertility (Nguyen et al., 2017a), confirming the observations of Ravagnolo and Misztal (2000).

Animals identified to be divergent for heat susceptibility using the genomic breeding values developed by Nguyen et al. (2016) had significant differences in milk yield losses, rectal and intra-vaginal temperatures under conditions emulating a mild heat wave (Garner et al., 2016). Since these studies, additional animals have been added to the reference population (mainly genotyped females) enabling breeding values for heat tolerance to be released for the first time in Australia in 2017 (Nguyen et al., 2017a). Reliabilities for bulls with no progeny are typically around $40 \%$. Note that the heat tolerance EBV is not currently included in the Balanced Performance Index (BPI). However, the advice given by DataGene (Bundoora, Australia) to farmers who wish to select for heat tolerance is to choose high EBV sires that are also high for BPI. DataGene developed a mobile phone app (Good Bulls; available for Android and Apple), that allows farmers to customize selection indices through applying minimum selection criteria to all calculated EBV, such as heat tolerance. Anecdotally the EBV has been especially popular in the northern milk production states in Australia, such as New South Wales and Queensland (Michelle Axford, DataGene, Bundoora, Australia).

One of the challenges with including heat tolerance in the BPI is that Australia is a large country with very diverse climates, so the economic value of selecting for heat tolerance may vary by region. For instance, where the environmental heat load is higher, there may be more justification in selecting for heat tolerance than regions with lower heat load. Using projected climate data from the Commonwealth Scientific and Industrial
Research Organisation (CSIRO; Canberra, Australia) and the Bureau of Meteorology, Nguyen et al. (2017b) determined levels of heat load for various dairying regions in Australia and used this information as weights for heat tolerance in an adapted version of the BPI. The Pearson correlation between the 2 indices [i.e., BPI and the BPI with heat tolerance (with weights appropriate for a high THI environment)] was around 0.95, which implies that there is currently no justification to have regionally specific indices. In addition to this, estimates of genotype by environment interaction $(\mathrm{G} \times \mathrm{E})$ for heat tolerance in Australia show that even at extreme THI, re-ranking is minor [i.e., genetic correlations between milk production traits at high and low THI are $>0.8$ (Hayes et al., 2003; Haile-Mariam et al., 2008)]. However, selecting for robustness (i.e., similar EBV across environments) could be an option for ensuring stable performance (König and May, 2019). Additionally, education on customized indices, using apps such as Good Bulls, could help farmers improve decision making.

\section{FUTURE RESEARCH}

High-throughput phenotyping of new selection criteria for heat tolerance and methane emissions is likely to become a focal point of research in this area over the next decade. The further development of sensors and automated data collection and storage applied to dedicated genotyped populations will ensure that the next generation of genomic breeding values will be closer to the biology of the underpinning traits. This is of great importance in reducing the global footprint of dairy animals in addition to being able to adapt to a warming environment. It is possible that this research will become dominated by commercial companies looking for points of differentiation from their competitors. However, the academic sector will still play an important role in developing the strategies and methods that can then be applied in addition to educating end users. In fact, it should be noted that considerably more progress can be made through sharing data on deeply phenotyped genomic reference populations with the research community.

It is plausible that a multi-omics approach to addressing both heat tolerance and methane emissions will become important over the next decade. Examples of a multi-omics data set include some of the following: direct and indirect selection criteria, the metagenome (e.g., rumen, reproductive, and so on), use of MIR spectral data (available on cows enrolled in milk recording), in addition to complementary targeted data sets from the proteome/metabolome (protein and metabolite structure and function) and functional genomic assays (e.g., methylation, transcriptomics, and so on). When 
these approaches are used with whole-genome sequencing, causal variants can be identified, which should lead to improved responses to selection. If variants of large effect are found, then these could become candidates for gene editing. A multi-omics approach in a collaborative environment could revolutionize genomic selection of methane emission and heat tolerance traits in addition to many other traits.

\section{CONCLUSIONS}

Genetic improvement will play a key role in reducing the contribution of ruminants to climate change in addition to providing cattle that are heat tolerant. Genomic selection has been an enabling technology to generate breeding values for heat tolerance and reduced methane emissions. New ways of phenotyping (e.g., using sensors or MIR) are likely to become important to generate sufficient data for genomic prediction, with international collaboration playing an important role in assembling large quantities of high-quality phenotypes.

\section{ACKNOWLEDGMENTS}

The authors thank DairyBio, jointly funded by Dairy Australia (Melbourne, Australia), the Gardiner Dairy Foundation (Melbourne, Australia), and Agriculture Victoria (Melbourne, Australia), for funding. Many thanks to colleagues at Agriculture Victoria Research (Bundoora and Ellinbank, Australia) and DataGene (Bundoora, Australia) for discussions that helped shape this paper, with special thanks to Thuy Nguyen (Agriculture Victoria Research, Bundoora, Australia). The authors have not stated any conflicts of interest.

\section{REFERENCES}

Bar, D., M. Kaim, I. Flamenbaum, B. Hanochi, and R. L. ToaffRosenstein. 2019. Technical note: Accelerometer-based recording of heavy breathing in lactating and dry cows as an automated measure of heat load. J. Dairy Sci. 102:3480-3486. https://doi .org/10.3168/jds.2018-15186.

Bell, M., P. Garnsworthy, A. Stott, and J. E. Pryce. 2015. Effects of changing cow production and fitness traits on profit and greenhouse gas emissions of UK dairy systems. J. Agric. Sci. 153:138151. https://doi.org/10.1017/S0021859614000847.

Bell, M. J., R. J. Eckard, M. Haile-Mariam, and J. E. Pryce. 2013. The effect of changing cow production and fitness traits on net income and greenhouse gas emissions from Australian dairy systems. J. Dairy Sci. 96:7918-7931. https://doi.org/10.3168/jds.2012-6289.

Bernabucci, U., S. Biffani, L. Buggiotti, A. Vitali, N. Lacetera, and A. Nardone. 2014. The effects of heat stress in Italian Holstein dairy cattle. J. Dairy Sci. 97:471-486. https://doi.org/10.3168/jds.2013 $-6611$.

Berry, D. P., M. Coffey, J. Pryce, Y. de Haas, P. Løvendahl, N. Krattenmacher, J. Crowley, Z. Wang, D. Spurlock, K. Weigel, K. Macdonald, and R. F. Veerkamp. 2014. International genetic evaluations for feed intake in dairy cattle through the collation of data from multiple sources. J. Dairy Sci. 97:3894-3905. https://doi.org/ 10.3168/jds.2013-7548.

Berry, D. P., and J. Crowley. 2013. Cell Biology Symposium: Genetics of feed efficiency in dairy and beef cattle. J. Anim. Sci. 91:15941613. https://doi.org/10.2527/jas.2012-5862.

Bohmanova, J., I. Misztal, and J. B. Cole. 2007. Temperature-humidity indices as indicators of milk production losses due to heat stress. J. Dairy Sci. 90:1947-1956. https://doi.org/10.3168/jds.2006-513.

Breider, I. S., E. Wall, and P. C. Garnsworthy. 2019. Short communication: Heritability of methane production and genetic correlations with milk yield and body weight in Holstein-Friesian dairy cows. J. Dairy Sci. 102:7277-7281. https://doi.org/10.3168/jds.2018-15909.

Britt, J. H., R. A. Cushman, C. D. Dechow, H. Dobson, P. Humblot, M. F. Hutjens, G. A. Jones, P. S. Ruegg, I. M. Sheldon, and J. S. Stevenson. 2018. Invited review: Learning from the future $-\mathrm{A}$ vision for dairy farms and cows in 2067. J. Dairy Sci. 101:3722-3741. https://doi.org/10.3168/jds.2017-14025.

Bryant, J., N. López-Villalobos, J. Pryce, C. Holmes, and D. Johnson. 2007. Quantifying the effect of thermal environment on production traits in three breeds of dairy cattle in New Zealand. N. Z. J. Agric. Res. 50:327-338. https://doi.org/10.1080/00288230709510301.

Burrow, H. M., B. J. Mans, F. F. Cardoso, M. A. Birkett, A. C. Kotze, B. J. Hayes, N. Mapholi, K. Dzama, M. C. Marufu, N. W. Githaka, and A. Djikeng. 2019. Towards a new phenotype for tick resistance in beef and dairy cattle: A review. Anim. Prod. Sci. 59:1401-1427. https://doi.org/10.1071/AN18487.

Campa, C. C., N. R. Weisbach, A. J. Santinha, D. Incarnato, and R. J. Platt. 2019. Multiplexed genome engineering by Cas12a and CRISPR arrays encoded on single transcripts. Nat. Methods 16:887-893. https://doi.org/10.1038/s41592-019-0508-6.

Capper, J. L., and D. E. Bauman. 2013. The role of productivity in improving the environmental sustainability of ruminant production systems. Annu. Rev. Anim. Biosci. 1:469-489. https://doi.org/10 .1146/annurev-animal-031412-103727.

Capper, J. L., and R. Cady. 2012. A comparison of the environmental impact of Jersey compared with Holstein milk for cheese production. J. Dairy Sci. 95:165-176. https://doi.org/10.3168/jds.2011 -4360 .

Capper, J. L., R. Cady, and D. Bauman. 2009. The environmental impact of dairy production: 1944 compared with 2007. J. Anim. Sci. 87:2160-2167. https://doi.org/10.2527/jas.2009-1781.

Carabaño, M. J., M. Ramón, A. Menéndez-Buxadera, A. Molina, and C. Díaz. 2019. Selecting for heat tolerance. Anim. Front. 9:62-68. https://doi.org/10.1093/af/vfy033.

Chesnais, J., T. Cooper, G. Wiggans, M. Sargolzaei, J. Pryce, and F. Miglior. 2016. Using genomics to enhance selection of novel traits in North American dairy cattle. J. Dairy Sci. 99:2413-2427. https: //doi.org/10.3168/jds.2015-9970.

CSIRO and Bureau of Meteorology. 2015. Climate change in Australia: Technical report, CSIRO Marine and Atmospheric Research. CSIRO and Bureau of Meteorology, Aspendale, Australia.

Dahl, G. E., S. Tao, and A. P. A. Monteiro. 2016. Effects of lategestation heat stress on immunity and performance of calves. J. Dairy Sci. 99:3193-3198. https://doi.org/10.3168/jds.2015-9990.

Danielsson, R., J. Dicksved, L. Sun, H. Gonda, B. Müller, A. Schnürer, and J. Bertilsson. 2017. Methane production in dairy cows correlates with rumen methanogenic and bacterial community structure. Front. Microbiol. 8:226. https://doi.org/10.3389/fmicb.2017 .00226 .

Das, R., L. Sailo, N. Verma, P. Bharti, J. Saikia, Imtiwati, and R. Kumar. 2016. Impact of heat stress on health and performance of dairy animals: A review. Vet. World 9:260-268. https://doi.org/10 .14202 /vetworld.2016.260-268.

Davis, S. R., R. J. Spelman, and M. D. Littlejohn. 2017. Breeding heat tolerant dairy cattle: The case for introgression of the "slick" prolactin receptor variant into Bos taurus dairy breeds. J. Anim. Sci. 95:1788-1800. https://doi.org/10.2527/jas.2016.0956.

de Haas, Y., M. Pszczola, H. Soyeurt, E. Wall, and J. Lassen. 2017. Invited review: Phenotypes to genetically reduce greenhouse gas emissions in dairying. J. Dairy Sci. 100:855-870. https://doi.org/ 10.3168/jds.2016-11246. 
de Haas, Y., J. Windig, M. Calus, J. Dijkstra, M. De Haan, A. Bannink, and R. Veerkamp. 2011. Genetic parameters for predicted methane production and potential for reducing enteric emissions through genomic selection. J. Dairy Sci. 94:6122-6134. https://doi .org/10.3168/jds.2011-4439.

Dehnavi, E., S. A. Mahyari, F. S. Schenkel, and M. Sargolzaei. 2018. The effect of using cow genomic information on accuracy and bias of genomic breeding values in a simulated Holstein dairy cattle population. J. Dairy Sci. 101:5166-5176. https://doi.org/10.3168/ jds.2017-12999.

De Marchi, M., V. Toffanin, M. Cassandro, and M. Penasa. 2014. Invited review: Mid-infrared spectroscopy as phenotyping tool for milk traits. J. Dairy Sci. 97:1171-1186. https://doi.org/10.3168/ jds.2013-6799.

Denninger, T. M., F. Dohme-Meier, L. Eggerschwiler, A. Vanlierde, F. Grandl, B. Gredler, M. Kreuzer, A. Schwarm, and A. Münger., 2019. Persistence of differences between dairy cows categorized as low or high methane emitters, as estimated from milk mid-infrared spectra and measured by GreenFeed. J. Dairy Sci. 102:1175111765.

De Rensis, F. D., and R. J. Scaramuzzi. 2003. Heat stress and seasonal effects on reproduction in the dairy cow - A review. Theriogenology 60:1139-1151. https://doi.org/10.1016/S0093-691X(03)00126 -2 .

Dikmen, S., J. B. Cole, D. J. Null, and P. J. Hansen. 2012. Heritability of rectal temperature and genetic correlations with production and reproduction traits in dairy cattle. J. Dairy Sci. 95:3401-3405. https://doi.org/10.3168/jds.2011-4306.

Dikmen, S., F. A. Khan, H. J. Huson, T. S. Sonstegard, J. I. Moss, G. E. Dahl, and P. J. Hansen. 2014. The SLICK hair locus derived from Senepol cattle confers thermotolerance to intensively managed lactating Holstein cows. J. Dairy Sci. 97:5508-5520. https:// doi.org/10.3168/jds.2014-8087.

Garner, J. B., M. L. Douglas, S. R. O. Williams, W. J. Wales, L. C. Marett, T. T. T. Nguyen, C. M. Reich, and B. J. Hayes. 2016. Genomic selection improves heat tolerance in dairy cattle. Sci. Rep. 6:34114. https://doi.org/10.1038/srep34114.

Garnsworthy, P. C. 2004. The environmental impact of fertility in dairy cows: A modelling approach to predict methane and ammonia emissions. Anim. Feed Sci. Technol. 112:211-223. https://doi .org/10.1016/j.anifeedsci.2003.10.011.

Gaughan, J. B., T. L. Mader, S. M. Holt, and A. Lisle. 2008. A new heat load index for feedlot cattle. J. Anim. Sci. 86:226-234. https: //doi.org/10.2527/jas.2007-0305.

Gerber, P. J., A. N. Hristov, B. Henderson, H. Makkar, J. Oh, C. Lee, R. Meinen, F. Montes, T. Ott, J. Firkins, A. Rotz, C. Dell, A. T. Adesogan, W. Z. Yang, J. M. Tricarico, E. Kebreab, G. Waghorn, J. Dijkstra, and S. Oosting. 2013. Technical options for the mitigation of direct methane and nitrous oxide emissions from livestock: A review. Animal 7(Suppl. 2):220-234. https://doi.org/10.1017/ S1751731113000876.

Gonzalez-Recio, O., M. Coffey, and J. Pryce. 2014. On the value of the phenotypes in the genomic era. J. Dairy Sci. 97:7905-7915. https: //doi.org/10.3168/jds.2014-8125.

Haas, Y. d., E. Wall, P. C. Garnsworthy, B. Kuhla, E. Negussie, and J. Lassen. 2018. Where have we come with breeding for methane emissions: update from international collaborations. In Proceedings of the World Congress on Genetics Applied to Livestock Production: Volume Challenges - Environmental (Vol. 11.810). http: //www.wcgalp.org/.

Haile-Mariam, M., M. J. Carrick, and M. E. Goddard. 2008. Genotype by environment interaction for fertility, survival, and milk production traits in Australian dairy cattle. J. Dairy Sci. 91:4840-4853. https://doi.org/10.3168/jds.2008-1084.

Hammami, H., J. Vandenplas, M. L. Vanrobays, B. Rekik, C. Bastin, and N. Gengler. 2015. Genetic analysis of heat stress effects on yield traits, udder health, and fatty acids of Walloon Holstein cows. J. Dairy Sci. 98:4956-4968. https://doi.org/10.3168/jds.2014 -9148 .

Hammond, K. J., L. A. Crompton, A. Bannink, J. Dijkstra, D. R. Yáñez-Ruiz, P. O’Kiely, E. Kebreab, M. A. Eugène, Z. Yu, K. J.
Shingfield, A. Schwarm, A. N. Hristov, and C. K. Reynolds. 2016. Review of current in vivo measurement techniques for quantifying enteric methane emission from ruminants. Anim. Feed Sci. Technol. 219:13-30. https://doi.org/10.1016/j.anifeedsci.2016.05.018.

Hansen, P. J. 2007. Exploitation of genetic and physiological determinants of embryonic resistance to elevated temperature to improve embryonic survival in dairy cattle during heat stress. Theriogenology 68:S242-S249. https://doi.org/10.1016/j.theriogenology.2007 .04 .008 .

Hayes, B. J., M. Carrick, P. Bowman, and M. E. Goddard. 2003. Genotype $\times$ environment interaction for milk production of daughters of Australian dairy sires from test-day records. J. Dairy Sci 86:3736-3744. https://doi.org/10.3168/jds.S0022-0302(03)73980 -0 .

Hill, J., C. McSweeney, A.-D. G. Wright, G. Bishop-Hurley, and K. Kalantar-zadeh. 2016. Measuring methane production from ruminants. Trends Biotechnol. 34:26-35. https://doi.org/10.1016/j .tibtech.2015.10.004.

IPCC. 2013. Climate Change 2013: The Physical Science Basis. Contribution of Working Group Fifth Assessment Report of the Intergovernmental Panel on Climate Change. http://www .climatechange2013.org/images/report/WG1AR5_Frontmatter _FINAL.pdf.

Johnson, K. A., and D. E. Johnson. 1995. Methane emissions from cattle. J. Anim. Sci. 73:2483-2492. https://doi.org/10.2527/1995 $.7382483 x$.

Khansefid, M., J. Pryce, S. Bolormaa, S. Miller, Z. Wang, C. Li, and M. Goddard. 2014. Estimation of genomic breeding values for residual feed intake in a multibreed cattle population. J. Anim. Sci. 92:3270-3283. https://doi.org/10.2527/jas.2014-7375.

König, S., and K. May. 2019. Invited review: Phenotyping strategies and quantitative-genetic background of resistance, tolerance and resilience associated traits in dairy cattle. Animal 13:897-908.

Lassen, J., and P. Løvendahl. 2016. Heritability estimates for enteric methane emissions from Holstein cattle measured using noninvasive methods. J. Dairy Sci. 99:1959-1967.

LeRoy Hahn, G., J. B. Gaughan, T. L. Mader, and R. A. Eigenberg. 2009. Chapter 5: Thermal Indices and Their Applications for Livestock Environments. Pages 113-130 in Livestock Energetics and Thermal Environmental Management Chapter 5. American Society of Agricultural and Biological Engineers, St. Joseph, MI.

Littlejohn, M. D., K. M. Henty, K. Tiplady, T. Johnson, C. Harland, T. Lopdell, R. G. Sherlock, W. Li, S. D. Lukefahr, B. C. Shanks, D. J. Garrick, R. G. Snell, R. J. Spelman, and S. R. Davis. 2014 Functionally reciprocal mutations of the prolactin signalling pathway define hairy and slick cattle. Nat. Commun. 5:5861. https:// doi.org/10.1038/ncomms6861.

Liu, H., V. Vaddella, and D. Zhou. 2011. Effects of chestnut tannins and coconut oil on growth performance, methane emission, ruminal fermentation, and microbial populations in sheep. J. Dairy Sci. 94:6069-6077. https://doi.org/10.3168/jds.2011-4508.

Mackinnon, M. J., K. Meyer, and D. J. S. Hetzel. 1991. Genetic variation and covariation for growth, parasite resistance and heat tolerance in tropical cattle. Livest. Prod. Sci. 27:105-122. https://doi .org/10.1016/0301-6226(91)90090-D

Manzanilla-Pech, C. I. V., Y. De Haas, B. J. Hayes, R. F. Veerkamp, M. Khansefid, K. A. Donoghue, P. F. Arthur, and J. E. Pryce. 2016. Genomewide association study of methane emissions in Angus beef cattle with validation in dairy cattle. J. Anim. Sci. 94:4151-4166. https://doi.org/10.2527/jas.2016-0431.

Mc Hugh, N., T. H. E. Meuwissen, A. R. Cromie, and A. K. Sonesson. 2011. Use of female information in dairy cattle genomic breeding programs. J. Dairy Sci. 94:4109-4118. https://doi.org/10.3168/jds .2010-4016.

Moate, P. J., M. H. Deighton, S. R. O. Williams, J. E. Pryce, B. J. Hayes, J. L. Jacobs, R. J. Eckard, M. C. Hannah, and W. J. Wales. 2016. Reducing the carbon footprint of Australian milk production by mitigation of enteric methane emissions. Anim. Prod. Sci 56:1017-1034. https://doi.org/10.1071/AN15222.

Negussie, E., Y. de Haas, F. Dehareng, R. J. Dewhurst, J. Dijkstra, N. Gengler, D. P. Morgavi, H. Soyeurt, S. van Gastelen, T. Yan, and 
F. Biscarini. 2017. Invited review: Large-scale indirect measurements for enteric methane emissions in dairy cattle: A review of proxies and their potential for use in management and breeding decisions. J. Dairy Sci. 100:2433-2453. https://doi.org/10.3168/ jds.2016-12030.

Nguyen, T. T. T., P. J. Bowman, M. Haile-Mariam, G. J. Nieuwhof, B. J. Hayes, and J. E. Pryce. 2017a. Short communication: Implementation of a breeding value for heat tolerance in Australian dairy cattle. J. Dairy Sci. 100:7362-7367. https://doi.org/10.3168/ jds.2017-12898.

Nguyen, T. T. T., P. J. Bowman, M. Haile-Mariam, J. E. Pryce, and B. J. Hayes. 2016. Genomic selection for tolerance to heat stress in Australian dairy cattle. J. Dairy Sci. 99:2849-2862. https://doi .org/10.3168/jds.2015-9685.

Nguyen, T. T. T., B. J. Hayes, and J. E. Pryce. 2017b. A practical future-scenarios selection tool to breed for heat tolerance in Australian dairy cattle. Anim. Prod. Sci. 57:1488-1493. https://doi .org/10.1071/AN16449.

Pryce, J. E., and M. J. Bell. 2017. The impact of genetic selection on greenhouse-gas emissions in Australian dairy cattle. Anim. Prod. Sci. 57:1451-1456.

Pryce, J. E., T. T. T. Nguyen, M. Axford, G. Nieuwhof, and M. Shaffer. 2018. Symposium review: Building a better cow; The Australian experience and future perspectives. J. Dairy Sci. 101:37023713. https://doi.org/10.3168/jds.2017-13377.

Ravagnolo, O., and I. Misztal. 2000. Genetic component of heat stress in dairy cattle, parameter estimation. J. Dairy Sci. 83:2126-2130. https://doi.org/10.3168/jds.S0022-0302(00)75095-8.

Rexroad, C., J. Vallet, L. K. Matukumalli, J. Reecy, D. Bickhart, H. Blackburn, M. Boggess, H. Cheng, A. Clutter, N. Cockett, C. Ernst, J. E. Fulton, J. Liu, J. Lunney, H. Neibergs, C. Purcell, T. P. L. Smith, T. Sonstegard, J. Taylor, B. Telugu, A. V. Eenennaam, C. P. V. Tassell, and K. Wells. 2019. Genome to phenome: Improving animal health, production, and well-being - A new USDA blueprint for animal genome research 2018-2027. Front. Genet. 10:327. https://doi.org/10.3389/fgene.2019.00327.

Richardson, C. M., C. F. Baes, P. R. Amer, C. Quinton, P. Martin, V. R. Osborne, J. E. Pryce, and F. Miglior. 2020. Determining the economic value of daily dry matter intake and associated methane emissions in dairy cattle. Animal 14:171-179.

Ríus, A. G. 2019. Invited Review: Adaptations of protein and amino acid metabolism to heat stress in dairy cows and other livestock species. Appl. Anim. Sci. 35:39-48. https://doi.org/10.15232/aas .2018-01805.

Van Eenennaam, A. L. 2019. Application of genome editing in farm animals: Cattle. Transgenic Res. 28(S2):93-100. https://doi.org/ 10.1007/s11248-019-00141-6.

Vanlierde, A., H. Soyeurt, N. Gengler, F. G. Colinet, E. Froidmont, M. Kreuzer, F. Grandl, M. Bell, P. Lund, D. W. Olijhoek, M.
Eugène, C. Martin, B. Kuhla, and F. Dehareng. 2018. Short communication: Development of an equation for estimating methane emissions of dairy cows from milk Fourier transform mid-infrared spectra by using reference data obtained exclusively from respiration chambers. J. Dairy Sci. 101:7618-7624. https://doi.org/10 $.3168 /$ jds.2018-14472.

Vanlierde, A., M. L. Vanrobays, F. Dehareng, E. Froidmont, H. Soyeurt, S. McParland, E. Lewis, M. H. Deighton, F. Grandl, M. Kreuzer, B. Gredler, P. Dardenne, and N. Gengler. 2015. Hot topic: Innovative lactation-stage-dependent prediction of methane emissions from milk mid-infrared spectra. J. Dairy Sci. 98:57405747. https://doi.org/10.3168/jds.2014-8436.

Waghorn, G. C., H. Clark, V. Taufa, and A. Cavanagh. 2008. Monensin controlled-release capsules for methane mitigation in pasturefed dairy cows. Aust. J. Exp. Agric. 48:65-68. https://doi.org/10 .1071/EA07299.

Wallace, R. J., G. Sasson, P. C. Garnsworthy, I. Tapio, E. Gregson, P. Bani, P. Huhtanen, A. R. Bayat, F. Strozzi, F. Biscarini, T. J. Snelling, N. Saunders, S. L. Potterton, J. Craigon, A. Minuti, E. Trevisi, M. L. Callegari, F. P. Cappelli, E. H. Cabezas-Garcia, J. Vilkki, C. Pinares-Patino, K. O. Fliegerová, J. Mrázek, H. Sechovcová, J. Kopečný, A. Bonin, F. Boyer, P. Taberlet, F. Kokou, E. Halperin, J. L. Williams, K. J. Shingfield, and I. Mizrahi. 2019. A heritable subset of the core rumen microbiome dictates dairy cow productivity and emissions. Science Advances 5:eaav8391.

Wang, Q., and H. Bovenhuis. 2019. Validation strategy can result in an overoptimistic view of the ability of milk infrared spectra to predict methane emission of dairy cattle. J. Dairy Sci. 102:6288-6295. https://doi.org/10.3168/jds.2018-15684.

West, J. W. 2003. Effects of heat-stress on production in dairy cattle. J. Dairy Sci. 86:2131-2144. https://doi.org/10.3168/jds.S0022 $-0302(03) 73803-\mathrm{X}$.

Williams, Y. J., S. Popovski, S. M. Rea, L. C. Skillman, A. F. Toovey, K. S. Northwood, and A.-D. G. Wright. 2009. A vaccine against rumen methanogens can alter the composition of archaeal populations. Appl. Environ. Microbiol. 75:1860-1866. https://doi.org/10 .1128/AEM.02453-08.

Zhang, X., P. R. Amer, G. M. Jenkins, J. A. Sise, B. Santos, and C. Quinton. 2019. Prediction of effects of dairy selection indexes on methane emissions. J. Dairy Sci. 102:11153-11168. https://doi .org/10.3168/jds.2019-16943.

\section{ORCIDS}

Jennie E. Pryce () https://orcid.org/0000-0002-1397-1282 Mekonnen Haile-Mariam @ https://orcid.org/0000-0001-5476-7475 